\title{
Hunting the Beast on YouTube
}

\author{
The Framing of Nature in Social Media
}

\author{
Cecilia Mörner \& Ulrika Olausson
}

\begin{abstract}
Humans' perceived relationship to nature and non-human lifeforms is fundamental for sustainable development; different framings of nature - as commodity, as threat, as sacred etc. - imply different responses to future challenges. The body of research on nature representations in various symbolic contexts is growing, but the ways in which nature is framed by people in the everyday has received scant attention. This paper aims to contribute to our understanding of the framing of nature by studying how wild-boar hunting is depicted on YouTube. The qualitative frame analysis identified three interrelated frames depicting hunting as battle, as consumption, and as privilege, all of which constitute and are constituted by the underlying notion of human as superior to nature. It is suggested that these hegemonic nature frames suppress more constructive ways of framing the human-nature relationship, but also that the identification of such potential counter-hegemonic frames enables their discursive manifestation.
\end{abstract}

Keywords: nature-culture, frame analysis, visual analysis, social media, film analysis, hunting

\section{Introduction}

Perceptions about humans' relationship with nature and other species are of fundamental importance to sustainable development. As argued by Macnaghten and Urry (1998: 3 ), 'an appropriate politics of nature would be one which stems from how people talk about and conceptualize nature in their day-to-day lives, in their localities and other "communities"'. Cultural meaning influences the ways in which humans interact with non-human life forms (Williams 1980), which means that discursive constructions of nature not only result in a material impact, but also serve to justify and reinforce these material practices (Milstein 2009). For instance, if people think and talk about nature as a threat, activities such as poaching will be legitimised and reproduced. Thus, improved knowledge is needed about nature representations among people in the everyday in order to meet the sustainability challenges ahead; different representations of nature - as commodity, as threatened, as threat, as sacred, as stable, as remote, etc. - imply different responses to future challenges (Cox 2007). 
The body of research on representations of nature has grown in recent decades. There is extensive feminist scholarship on the parallels between sex vs. gender or female vs. male, and the nature-culture dichotomy (e.g. Merchant 1990; Ortner 1974; Plumwood 1997), with wildlife films on television being one case in point (Ganetz 2004). There are studies showing how modern zoos can be viewed as symbols of imperial power and celebrations of the domination of nature (DeLuca \& Slawter-Volkening 2009; cf. Milstein 2009), and how the animal industry discursively reproduces an oppressive and exploitative view of non-human species (Stibbe 2001). Uggla and Olausson (2013) demonstrated ways in which nature is symbolically 'otherised' in tourist information, and as such is positioned as a commodity to be consumed by culture. The nature-culture dichotomy has been identified by Uggla (2010) in policy discourse on climate change and biodiversity, by Cassidy and Mills (2012) in a study of media representations of 'urban foxes', and by Seegert (2014) when demonstrating how 'Bruno the bear' rhetorically queered the anthropogenic landscape. Attempting to problematise this well-defined discursive division between nature and culture, Sowards (2006) demonstrated how identification with orangutans might provide an opportunity for humans to look beyond this dualism, and Milstein (2008) explored how communication mediates human-nature relationships by viewing nature not as mute but as an active agent in the communication process. Ecocritical studies of nature representations in movies, novels, poems, and other kinds of media texts have demonstrated that human's relationship to nature shows signs of anxiety and ambivalence, in that it includes on the one hand the modern understanding of humans as superior to nature - the right of people to enjoy and exploit nature on their own terms - and on the other hand, the stewardship function of humans - to care for and conserve nature (e.g. Buell 2005; Garrard 2012). ${ }^{1}$

In sum, there is quite extensive literature on nature representations in various discursive contexts. However, the ways in which nature is framed in everyday discourse have received scant attention. Champ, Williams and Lundy (2013) suggested the analysis of on-line communication, in their case blogs, to capture narratives about people's relationship to nature and wilderness. In this connection, we would argue that social media such as Facebook, Twitter, and YouTube must be regarded as particularly relevant objects for empirical research. These media offer a wide range of opportunities for discursively framing nature; there are groups, hash-tags, videos, etc. pertaining to climate change, wildlife management, and green energy, just to mention a few. Network society (Castells 2005) has fostered a 'participatory culture' of prod-using and sharing (Cardoso 2012; Jenkins 2009), which means that nature frames are rapidly circulated among large groups of people, who, in turn, might reinforce, negotiate and oppose the frames as communicated in news feeds, tweets, visuals, and videos. Hence, social media constitute an unprecedented opportunity to investigate the framing of nature by people in different contexts.

The current study aims to contribute to our understanding of how nature is framed by people in the everyday by studying depictions of wild-boar hunting on the video-sharing site YouTube. Founded in the USA in 2005, and with several European local versions starting in 2007 and 2008, YouTube is the world's largest archive of moving images as well as 'a rupture in the producer/consumer model of the cultural industries' (Stiegler 2009: 41). Anyone can upload their own videos or clips from films onto YouTube at any time (Burgess \& Green 2009). In its capacity as one of the world's most popular websites, YouTube serves as an enormous arena for not only entertainment but all kinds 
of public perspectives on culture, politics and society, including people's perspectives on human being's relationship to nature.

As shown above, previous research has used various paths for the analytical operationalisation of the concept of nature and orangutans, bears, and wild life in general have functioned as study objects. This present study builds on the assumption that the practice of hunting in many ways brings the nature-culture relationship to a head. Culture has traditionally capitalised on the resources that wild animals provide, today perhaps more for the purpose of relaxation and leisure than for survival, at the same time as hunting is embedded in claims of stewardship - a necessary part of wildlife management - something which has lent widespread social acceptance to the practice.

Furthermore, attention to those parts of nature that commonly are considered as somewhat distasteful and without a clear ecological purpose is largely missing from previous research. There are culturally rooted assumptions that certain elements of nature, such as wild boars, are not worthy of respect or even decent treatment. Boars are not under threat of extinction. There are no 'save the boars' sites on the internet and boars do not appear on the covers of environmentalist journals. In the words of Cassidy and Mills (2012: 506) these 'animals' failure to conform to human conventions has often resulted in them being categorized as pests'. However, this study aspires to bridge this gap in the literature since the seemingly superfluous element of nature, such as wild boars, could serve as a 'critical case' (Esaiason, Gilljam, Oscarsson, \& Wängnerud 2012), with a potential to actualise straight-forward and uncensored framings of nature. Thus the critical case will facilitate the analytical identification of the 'pre-existing ways of imagining the place of humans in nature' (Garrard 2012: 2).

This article consists of four sections, including this introduction. The second section presents the analytical framework (framing theory), the materials, and the methods used for data analysis (qualitative content analysis and formal analysis). In the third section the results are presented and thematically structured around three interrelated frames that emerge from the analysis: (a) hunting as battle, (b) hunting as consumption, and (c) hunting as privilege. All of these constitute and are constituted by the notion of humans as superior to nature, implying a view of nature as something to be defeated, consumed, or dominated. The final section discusses the results and concludes that the hegemonic nature frames suppress alternative and more constructive ways of framing the humannature relationship, but also that the identification of such counter-hegemonic frames paves the way for responses that involve their discursive manifestation.

\section{Analytic framework, materials and method}

This study employs framing theory (Goffman 1974) to capture how wild-boar hunting is represented on YouTube. Within the field of environmental communication, frame analysis has generally been used in studying news media texts (e.g. Boykoff \& Boykoff 2007; Shehata \& Hopmann 2012); however, drawing as it does on literature from a range of disciplines including sociology, communications, linguistics, and psychology (Scheufele \& Tewksbury, 2007) it is applicable, as proposed by Uggla and Olausson (2013), to a wide range of textual materials.

Studying YouTube videos entails the inclusion of visual materials in the analysis. There is a growing body of visual analyses within the field of environmental commu- 
nication (e.g. DeLuca 1999; Peeples 2001), but for a long time they were marginalised within this research field in general (Hansen \& Machin 2013) and in frame analyses of the environment in particular. However, we would argue that visuals - stills as well as moving images - constitute excellent materials for the analysis of frames of any kind. The framing process should be seen as the construction of an interpretative framework for attaching meaning to events, processes, and phenomena (Goffman, 1974) and visuals arguably serve as powerful 'cognitive window(s)' (Pan \& Kosicki 1993: 59) through which the world receives meaning (e.g. Olsen, Finnegan, \& Hope 2008).

Framing is largely about salience; i.e. 'to frame is to select some aspects of a perceived reality and make them more salient in a communicating text' (Entman 1993: 52 , italics in original). This means that some pieces of information are, not necessarily intentionally, made more salient than others, which means in turn that other information is obscured or even omitted. Due to their seemingly factual and documentary character, wildlife videos on YouTube might give the deceptive impression of being transparent depictions of reality, i.e. of being free from framing processes such as those described above. (It is quite likely that most of the events that take place in the YouTube videos were not arranged for the recording but would have occurred in a similar way even if the camera were not there.) However, in addition to the fact that the videos are edited and soundtracks often have been added, framing is not something optional in communication; reality is always mediated through epistemology (Lakoff 2010). Thus, YouTube videos, like all forms of digital communication, are 'more than merely a reflection of unmediated experience with nature' (Champ et al. 2013: 136, italics in original).

When analysing frames, the analysis should not be reduced to mere topics or themes, or to identifying frames on the basis of individual texts/visual items (Carragee \& Roefs 2004; Reese, 2007). It is necessary to capture how frames work across various texts or visuals, and how they are organised around 'a central organizing idea or story line that provides meaning to an unfolding strip of events, weaving a connection among them' (Gamson \& Modigliani 1987: 53). The present analysis identifies three interrelated frames that cut across a number of videos. Along similar lines, several frames often co-exist within one single video even if, due to space constraints, the results presented below do not clearly show this.

\section{Materials and method for data analysis}

The selected materials consist of videos on wild-boar hunting from different parts of the world. The keywords 'boar hunting Europe 2012' were used in order to find videos that most likely would be in English ${ }^{2}$ and of manageable size. This resulted in 72 videos. 25 of these dealt primarily with topics other than hunting, for example skinning the animals, and seven focused mainly on hunting other kinds of animals, for example pheasants, and even fishing. Seven of the videos were professionally made and therefore removed from the sample, and finally, there were six duplicates resulting in 27 videos.

The final sample consisted of 27 DIY (Do-It-Yourself) videos which varied both in terms of national origin and form. 15 originated from the USA. One was shot in Argentina, one in Australia, one in New Zealand, one in South Africa, and one in Tanzania. Two were shot in Bosnia and Herzegovina, and one was from Croatia. Three were Hungarian and, finally, one video consisted of clips from other videos made in several different 
countries. The 11 videos used to empirically exemplify the analysis in the next section are typical examples of this larger body of analysed material, and presented in Table 1.

Table 1. YouTube Videos ${ }^{3}$

\begin{tabular}{|c|c|c|}
\hline Title & Country of Origin & Link \\
\hline Boar Hunt 1-22-2012 & US & http://www.youtube.com/watch?v=HrEQ4JtMQ0o \\
\hline $\begin{array}{l}\text { Graphic Boar Kill Shot. Drops pig } \\
\text { with archery shot, one arrow }\end{array}$ & US & http://www.youtube.com/watch?v=cV11wfQ14Mo \\
\hline Hog Kill Barnett Jackal Crossbow: & US & http://www.youtube.com/watch?v=rlfkjojQTU0 \\
\hline $\begin{array}{l}\text { The hunting of wild boars in } \\
\text { Hungary }\end{array}$ & Hungary & $\begin{array}{l}\text { http://www.xpatloop.com/news/the_hunting_of_ } \\
\text { wild_boars_in_hungary }\end{array}$ \\
\hline Piglet Headshot - Double Kill & US & http://www.youtube.com/watch?v=fgUAh6jYtOs \\
\hline Slovenian Crossbow hunting & Croatia & http://www.youtube.com/watch?v=6tTCiCRnDFA \\
\hline So Many Hogs... So Little Time & US & http://www.youtube.com/watch?v=xmLYNGDLqGs \\
\hline The Pig Hunters & New Zealand & http://www.youtube.com/watch?v=yuLQ0roOJ8w \\
\hline $\begin{array}{l}\text { 'Wet \& Hoggish' Russian Boar \& } \\
\text { Feral Hog Hunting }\end{array}$ & US & http://www.youtube.com/watch?v=ruU1yuDWNCg \\
\hline $\begin{array}{l}\text { European Wild Boar - } 08 \text { Feb } \\
\text { 2012.wmv }\end{array}$ & South Africa & https://www.youtube.com/watch?v=rWXiePpSzDk \\
\hline $\begin{array}{l}\text { Wild boar hunt } 1 / 2 \text { (Awesome kill } \\
\text { Shots) }\end{array}$ & US & http://www.youtube.com/watch?v=pslzMze9rNk \\
\hline
\end{tabular}

The boar-hunting videos were analysed qualitatively, and this study thus differs from the quantitative approaches (often content analysis) that dominate studies of media frames. The most suitable choice of qualitative method for frame analysis is not obvious, although established qualitative methods such as socio-semiotics or critical discourse analysis have successfully been employed in other studies (e.g. Gottdiener, 1995; Olausson, 2009). These methods are however primarily oriented towards text analysis, and in order to thoroughly operationalise the framing perspective in analysing moving images, we developed an analytical 'toolbox', drawing in part on the methodological devices of film studies (e.g. Bordwell \& Thompson, 2012). These tools served to identify the frame-shaping elements of the videos that render information salient. The analysis was carried out in two steps, the first being a qualitative content analysis and the second a formalistic analysis that focused on how the videos were made:

\section{Step 1 (qualitative content analysis):}

- Locations and activities. What surroundings, e.g. woods, fields, backyards, and activities, are granted prominence in the videos and thus made salient?

- Participants' appearances and attributes. What aspects of the hunt are made salient by means of the participants' self-presentation through clothing, weapons, facial expressions, talk, emotions, etc.?

- Boars'appearance and role. What aspects of the hunt are made salient by means of the presentation of the hunted boar and its role in the video? 
Step 2 (formalistic analysis):

- Close ups. How are close ups used to make certain aspects of the videos salient?

- Music and sound. How do soundtracks contribute to making certain information salient?

- Camera movements. How do camera movements render certain information salient?

- Editing. How do editing techniques such as cuts, slow/fast motion, and voice over work to make certain information salient?

These analytical tools have been systematically applied to each video in the sample and constitute the foundation of the analysis.

The study does not claim to contribute generalizable knowledge in a traditional statistical sense. Instead, the case of boar hunting on YouTube should be regarded as an exemplar (Flyvberg 2006), i.e. a case that illustrates the more general issue of humans' view of nature. The generality of the results should thus be viewed in theoretical terms as contributing to the body of knowledge about the discursive mechanisms that work to (re)produce certain understandings of humans' relationship to nature and non-human life forms.

\section{Results: Hunting the beast on YouTube}

This section presents the analysis of how boar hunting is framed in the YouTube videos analysed. The section is thematically structured around the central findings emerging from the analysis, where hunting is framed as (a) battle - viewing nature as an enemy to defeat; (b) consumption - viewing nature as a marketplace for consumption; and (c) privilege - viewing nature as something to be dominated in a traditional upper-class manner as a way to enact status.

\section{Hunting as battle}

One way of constructing the battle frame is by having the battles between men and boars take place in the woods, in swamps, and in other 'untamed' areas, and thus potentially dangerous, wild landscapes. For example, the main section of the DIY-video called Wild boar hunt 1/2 (Awesome kill Shots) is set in the woods. It consists of a montage of slowmotion pans of boars running, being shot, and falling to the ground, interspersed with close ups of hunters' tensed faces and weapons. A soundtrack consisting of a mixture of military music and light, popular music accompanies the montage. While the boars' flight through rough terrain emphasises the excitement of the wilderness known from wildlife films, novels, poems, dramas, action movies, and so forth, the soundtrack and the killing of the animals effectively construct nature as a battlefield such as we know it from war movies. In addition, the use of slow-motion strengthens the video's ties to battle scenes, and the close ups of the hunters' faces and loaded weapon stress the kill-or-bekilled aspect of cinematic representations of war, transforming the hunters into soldiers.

The DIY-video The Pig Hunters shows boars being chased by dogs in the wild mountainous landscape and a man dressed in camouflage with a knife, who grabs a fleeing boar that is tangled in bushes while the dogs attack it - all filmic elements that together 
contribute to the framing of hunting as a battle. This is also the case in the video Hog Kill Barnett Jackal Crossbow, where the camera zooms in on a group of boars from slightly above, and from the point-of-view of an invisible hunter, whose existence is indicated by whispers on the soundtrack and then confirmed when one of the boars is hit by an arrow coming from the direction of the camera. The boar falls to the ground, screaming and kicking; it rises, gets hit by another arrow, falls again, and continues to kick and scream for 50 seconds altogether. By lingering on the painful and drawn-out death of the boar, the battle frame is strengthened; the boar is the threatening enemy (of war), who is rightfully defeated and to whom no mercy should be given.

Some videos rely strongly on the framing of humans as soldiers in a battle even though they are set in places that do not connote danger at all. For example, Graphic Boar Heart Kill Shot. Drops pig with archery shot, one arrow, is set in what looks like a backyard. It includes a hunter, a boar, and a peacock, and the atmosphere is basically domestic. However, the hunter is dressed in camouflage clothing, a camouflage cap, and a balaclava covering most of his face. This outfit, along with the fact that he kills the boar at very close range, clearly constructs him as a soldier, even though the battlefield as such is absent and the boar appears to be more or less tame.

The video entitled Boar Hunt 1-22-2012 is another example of how the battle frame could be constructed despite the lack of any obvious battlefield setting. In this video, two men drag a wounded but still living boar out of a truck. Two other men with weapons join them. The men appear excited and laugh loudly. One of the armed men shoots the boar with a handgun. The other armed man hands him a rifle and he tries this weapon once before using the pistol again, this time at close range. Two young boys appear, one of whom is encouraged to shoot the boar with a BB gun. There is an apparent similarity to the logic of war films and shooter games such as 'Counter-Strike' and 'Halo', where an enemy, in this case the boar, should be terminated by any means necessary, without regrets but with excitement and triumph.

In Piglet Headshot - Double Kill the soundtrack plays a particularly important role in the construction of the battle frame. This video is filmed from a shooting tower where a hunter aims his rifle at a group of boars that have gathered at an arranged feeding place. Now and then the hunter addresses the camera, whispering things such as people who do not like watching boars getting killed should 'turn the channel to the Cartoon Network or something, 'cause it's fixing to get ugly'. In this way the hunter's comments effectively contribute to the construction of the battle frame - he is a soldier with a mission to kill. In addition, rock music is used in a way that creates a sense of battle through its connection to war movies and shooter games, first muted and then, starting when the first of altogether three boars is killed, loud and with a fast and energetic pace. The video ends with the hunter/soldier in camouflage clothing kneeling before the dead boars with gun in hand.

In sum, no matter if the setting is wild or domestic, there is always a possibility for humans to defeat the enemy, i.e. the wild boar, and this conquest is framed with a striking similarity to war and action movies, shooter games, and other products of popular culture that (re)construct the battle frame. Framing boar hunting as a battle means supporting the right of humans to outwit non-human species, and demonstrates pride in defeating nature. 


\section{Hunting as consumption}

In 'Wet \& Hoggish' Russian Boar \& Feral Hog Hunting, the location is not the wilderness but a boar ranch in Texas. Unlike in the battle frame analysed above, the main feature of the consumption frame is not the putting down of the animals but rather the process of going somewhere in order to consume. In this video, the Texas Lone Star Flag is waving in the wind and a country song is playing on the soundtrack, emphasising the geographic location that the hunters are visiting. The participants also orally recapitulate the previous day's hunting, when a woman successfully killed a boar, and comment about what kinds of weapons they use and how much they like to come to this place to relax and enjoy outdoor life. The actual killing is not shown. Instead there are plenty of shots of skinned corpses and suggestions about how to prepare the meat, followed by shots from the trip back home where the hunters happily display their hunting trophies while consuming whiskey.

Celebrating hunting products as a way to construct the consumption frame is evident in the video European Wild Boar - 08 Feb 2012.wmv. It begins and ends with a still image of a smiling young woman with a big rifle. Between the stills there is a brief moving shot of some boars in a barnyard, one of whom is shot to death. After killing the boar, the young woman's image is in colour instead of black and white like before, as if the killing made her feel more alive. The video is silent but it still manages to communicate a message: buy a weapon, kill a pig, and feel good about yourself.

It is stated above that the consumption frame does not primarily centre on the urge to kill, as the battle frame does. However, the joy of consuming can take the form of killing as many and as diverse boars as possible rather than using the appropriate equipment. In So Many Hogs ... So Little Time a hunter climbs up a tree in order to get a better view of the hunting site. The hunter has already been shown with a dead black boar, and now she says - addressing someone next to the camera but out of its frame - that she wants something 'a little bit more colourful'. Following this is a montage of different shots of a large number of boars, commented by the hunter's voiceover: 'You have black hogs... brown hogs... spotted hogs... red... you name it - they come in all colours!' In a later sequence, another hunter hangs up a camera in a tree, seemingly in order to predict where the boars are likely to show up. Time is precious, he says, and he does not want to go out in the woods without knowing in advance that the hunt will be successful. These commentaries exemplify the idea of nature as a marketplace. While the first hunter stresses the consumer's presumed desire for diversity, be it diversity of eye-shadow or boars, the second hunter represents a consumer who plans well, who carefully selects the shop that is most likely to stock the things he needs.

The consumption frame is well established in commercials, lifestyle magazines, lifestyle shows on television, lifestyle blogs, tourist information, and other media forms. It contributes to a view of 'commodification that has become so universalized as to seem well-nigh natural' (Jameson 1995/1992, p. 212) to the boar-hunting videos in a similar manner as, for example, television travel shows do to tourist destinations. Within the total system of capitalism anything can be (re)coded into the capitalistic logic, and many contemporary cultural texts construct nature in line with this logic as a place of leisure and consumption (Garrard 2012). Nature is a marketplace for people who are willing to pay to visit it (Ingram 2000) and offers both experiences and goods to the urban hunters. In the consumption frame, the hunters become tourists, detached from the activities and routines of everyday life and free from stress (Corbett 2006). Nature provides beautiful 
and exciting locations and scenery to be consumed by the tourist/hunter, at the same time as it is used to promote other objects of consumption such as whiskey and weapons. In this sense nature becomes 'a product itself that requires other products to be attainable' (Uggla \& Olausson 2013: 106).

\section{Hunting as privilege}

The privilege frame encapsulates the idea of hunting as something that should be performed in the same way as it always has. The hunters in The hunting of wild boars in Hungary appear calm, sober, and perhaps a bit stiff compared to those in the videos analysed above. Right after the opening credits there is a gathering outside a country house, represented through a montage of shots of mostly elderly men in traditional green hunting clothes and hats, accompanied by distinct timpani and strings on the soundtrack. The camera favours one male hunter in particular, who is casually yet conventionally dressed in a green cardigan, corduroys, and a hat, and easily distinguished by his beard. He is shown in a long shot resolutely walking through the woods followed by two other men, and later on, still in a determined fashion, gesticulating to somebody outside the camera frame. This man has next to nothing in common with the aggressive hunters that characterise the battle frame. Nor does he appear as a representative of consumption society, eager to collect trophies or consume goods. Instead, he is depicted as someone who hunts because he has the right and obligation to keep the hunting tradition alive; and the artistic music adds to this impression. We hardly hear him speak, and when he does say something it is just a few words in a low and calm voice. The slow fade out with a closing shot of a fire and two men blowing traditional horns further add to the framing of boar hunting as a matter of interacting with nature as a particular form of enacting status, something that representatives of the upper class have done for ages and that should not be called into question.

In Slovenian Crossbow Hunting, the privilege frame is constructed in a similar way. When an arrow hits the boar, the camera zooms in on the dying animal but quickly zooms out again, as if paying respect to the dead beast. The slightly blurred image, in combination with soft flutes on the soundtrack, lends a sober and almost melancholy atmosphere to the event. This is followed by a close-up of a hand showing the boar's wound, thereby displaying the hunter's skill and at the same time demonstrating that the arrow hit the heart and killed the boar instantly and without pain. The camera then zooms out and shows a hunter patting the carcass almost affectionately. This particular hunter is dressed in a Stetson hat and sunglasses that connote a modern western lifestyle and, together with shots of weapons and trophies, also contribute to the consumption frame. Both the way the hunter acts and the lingering tones of the flute neutralise his visual appearance and single him out as a man of class and traditional skills. Unlike the bearded man in The hunting of wild boars in Hungary the successful hunter in this video perhaps does not appear to be a man for whom conquering nature is his birth right, but he is clearly framed as at least associated with and accepted by the nobility. Both men are thus depicted as belonging to the upper class, and it is in their capacity as noble men that any potential questioning of the relationship between hunters and boars is undermined. All in all, the hunter's appearance and actions, also in the act of killing, provides the video with a sense of dignity and respect for the practice of hunting at the 
same time as human domination over nature is taken for granted in light of privilege and tradition. Nature is, and ought to remain subordinate to a man's will, the message reads.

The privilege frame includes a celebration of upper-class preferences and style and implies the enactment of status in the very interaction with nature. This frame might appear rather obsolete, and we believe that it is precisely its emphasis on the past that makes it potent enough to maintain and justify the right to dominate non-human species by birthright and privilege, as the way things have always been done. It is these kinds of culturally deeply rooted, naturalised, and taken-for-granted frames that are the most powerful factor in the (re)production of certain values, norms, and behaviours (Carragee \& Roefs 2004).

\section{Concluding discussion}

The analysis presented here demonstrates how three distinct but related frames intersect in the YouTube videos: (a) hunting as battle; (b) hunting as consumption; and (c) hunting as privilege. ${ }^{4}$ This view of nature as something to be defeated, consumed, or dominated is also found in numerous popular culture texts such as film and literature, where humans are sometimes depicted as acting out of greed and with no concern for nature, thereby provoking apocalyptic disasters (Dixon, 2003; Ivakhiv, 2008; Katerberg, 2008), but perhaps even more often as obliged to conquer and tame nature before taking care of it (Hartman 2007; Ingram 2000). One likely explanation of this resemblance between the nature frames as constructed in the studied YouTube videos and mainstream popular culture is the video format itself, and the producers' desire to mimic popular on-screen products. Another explanation, which operates on a deeper level, is that the framing of nature in both cases simultaneously constitutes and is constituted by the underlying 'organizing idea' (Gamson \& Modigliani 1987: 53) of a division between culture and nature with humans as the superior party. This belief, which to a large extent is taken for granted and naturalised, lends support and legitimacy to the notion that humans have the right and even obligation to defeat, consume, and dominate nature and non-human species. The modern understanding of the nature-culture relationship may be more ambiguous (Kaika, 2005) - humankind has been identified as both destroyer and saviour, and nature as both threat and refuge (Merchant 2003; Oelschlaeger 1991) - but it does presuppose that nature and culture are two distinct entities involved in an asymmetrical relationship where 'it is hardly nature that capitalizes on culture but rather the reverse' (Uggla \& Olausson 2013: 109).

Thus, the overarching organising idea of a human-nature divide, where humans are assigned the role as the superior party obliged to conquer and tame nature, permeates the three nature frames identified in this study. These hegemonic frames were detected through the analysis of what aspects of the hunt were made salient in the videos. However, for a frame analysis such as this one, it is important not only to attempt to determine the hegemonic frames, but also to point out what aspects are being omitted, obscured, or downplayed in the framing process, i.e. to identify the discursively suppressed counter-hegemonic frames (Carragee \& Roefs 2004). In order to discuss what counterhegemonic frames may be obscured in the studied materials, the three dialectics proposed by Milstein (2009) as generally permeating western discourse on the human-nature relationship, are helpful. These include mastery vs. harmony, othering vs. connection, 
and exploitation vs. idealism. The relationship between the two ends of each dichotomy is characterised by inequality; the discourses of mastery, othering, and exploitation are presumably hegemonic, whereas harmony, connection, and idealism should be seen as counter-hegemonic, i.e. as potential but rarely realised and manifested discourses.

When applying these dialectics to the results of the present study it becomes clear that all three identified frames, and perhaps the battle frame in particular, presuppose the othering of nature, a hegemonic discourse which 'serves not only to justify exploitative views and practices, but also to divorce humans from the knowledge that they are, in fact, animals and part of nature themselves' (Milstein 2009: 27). The very notion that non-human life forms are inferior 'others' informs and justifies the hunting frames, and the logical consequence is the discursive repression of the other pole of the dichotomy, connection. This counter-hegemonic discourse has the ability to neutralise the natureculture divide and instead acknowledge the interconnectedness between humans and non-human species (Milstein 2009).

In a similar manner, the hegemonic discourse of mastery preconditions all three frames, but is perhaps most visible in the construction of the privilege frame. Hunting might be regarded a 'deeply human practice', and therefore as connected to dwelling, i.e. a complete immersion in the natural world (Carbaugh \& Cerulli 2013: 10). However, the upper-class overtones of the privilege frame, suggesting that the right to dominate non-human species is given by inheritance and tradition, distinguishes it from dwelling. Arguably, the hunters of the privilege frame, despite their somewhat old-fashioned appearance, have little in common with the pre-colonial cultures that harmoniously adapted to and interconnected with nature (Milstein 2009). Thus, the counter-hegemonic discourse of harmony, which acknowledges a more equal and balanced relationship between humans and nature, is thus largely suppressed in the studied YouTube videos.

Finally, the discourse of exploitation works in a hegemonic manner across all three identified frames, and is particularly easy to recognise in the consumption frame. Here we find evidence that nature is framed 'as something that exists to be appropriated and commodified for ever-increasing accumulation and profits within global political economic frameworks' (Milstein 2009: 28). Such a framing implies the simultaneous repression of the other end of the dichotomy, the discourse of idealism which, according to Milstein (2009), can function as a creative force in rethinking the human-nature relationship to encompass more than just economic rationality.

To conclude, it is true that the present analysis might be regarded as yet another gloomy empirical confirmation that the discursive rift between nature and culture is utterly cemented and will never change. Nonetheless, however discouraging the results might seem at a first glance, they have also paved the way for the crystallization of the counter-hegemonic discourses (if only on a theoretical level) and this might bring some hope. As noted by Gamson (1988: 221) 'one cannot invoke the theme without making the countertheme relevant as well, and therein may lie opportunity'. Admittedly, it is highly unlikely that we will ever see a hunting video on YouTube where such counterhegemonic discourses are fully in play. However, by paying attention to these counterhegemonic discourses and encouraging their empirical manifestation in public discourse in general and policy discourse in particular, more constructive and beneficial discursive pathways, which are able to "provide the ideational ground for being "native to this place" we call nature/culture' (Willard 2008: 132) might not be entirely unthinkable. 


\section{Notes}

1. For poststructuralist perspectives on the nature-culture relationship, see Latour (1993) and Haraway (2003).

2. Wild boars are called European boars primarily in Scandinavian, Germanic and Anglo-Saxon culture.

3. Downloaded July 10, 2013

4. If one takes a closer look at the results of this study, the question of cultural differences in the framing of nature in social media arises. It appears as if the battle frame has an American bias, whereas the privilege frame seemingly occurs in the European videos. However, since the research design of this study does not allow for drawing such conclusions, the question must be left for future research.

\section{References}

Bordwell, David, \& Thompson, Kristin (2012). Film art: An introduction. London: McGraw-Hill.

Boykoff, Maxwell T., \& Boykoff, Jules M. (2007). Climate change and journalistic norms: A case-study of U.S. mass-media coverage. Geoforum, 38: 1190-1204.

Buell, Lawrence (2005). The future of environmental criticism: Environmental crisis and literary imagination. Malden, MA: Blackwell Publications.

Burgess, Jean E., \& Green, Joshua B. (2009). The entrepreneurial vlogger: Participatory culture beyond the professional-amateur divide, pp. 89-107 in Snickars, Pelle, \& Vonderau, Patrick (eds.) The YouTube reader. Stockholm: National Library of Sweden.

Carbaugh, Donal, \& Cerulli, Tovar (2013). Cultural discourses of dwelling: Investigating environmental communication as a place-based practice. Environmental Communication, 7(1): 4-23.

Cardoso, Gustavo (2012). Networked life world: Four dimensions of the cultures of networked belonging. Observatorio (OBS*) Journal, Special Issue: 197-205.

Carragee, Kevin M., \& Roefs, Wim (2004). The neglect of power in recent framing research. Journal of Communication, 54(2): 214-233.

Cassidy, Angela \& Mills, Brett (2012). "Fox tots attack shock": Urban foxes, mass media and boundarybreaching. Environmental Communication, 6(4): 494-511.

Castells, M. (2005). The rise of the network society: The information age: Economy, society and culture. London: Wiley.

Champ, Joseph G.; Williams, Daniel R., \& Lundy, Catherine M. (2013). An on-line narrative of Colorado wilderness: Self-in-“cybernetic space”. Environmental Communication, 7(1): 131-145.

Cox, Robert (2007). Nature's "crisis disciplines": Does environmental communication have an ethical duty? Environmental Communication, 1(1): 5-20.

Corbett, Julia B. (2006). Communicating nature. How we create and understand environmental messages. Washington: Island Press.

DeLuca, Kevin M. (1999). Image politics: The new rhetoric of environmental activism. New Jersey: Laurence Erlbaum Associates, Inc.

DeLuca, Kevin M., \& Slawter-Volkening, Lisa (2009). Memories of the Tropics in industrial jungles: Constructing nature, contesting nature. Environmental Communication, 3(1): 1-24.

Dixon, Wheeler W. (2003). Visions of the apocalypse: Spectacles of destruction in American cinema. London: Wallflower Press.

Entman, Robert M. (1993). Framing: Toward clarification of a fractured paradigm. Journal of Communication, 43: $52-58$

Esaiasson, Peter; Gilljam, Mikael; Oscarsson, Henrik, \& Wängnerud, Lena (2012). Metodpraktikan: Konsten att studera samhälle, individ och marknad [Handbook of methods: The art of studying society, individuals, and markets]. Stockholm: Norstedts Juridik.

Flyvberg, Bent (2006). Five misunderstandings about case-study research. Qualitative Inquiry, 12(2): 219-245.

Gamson, William A. (1988). Political discourse and collective action, pp. 219-244 in Klandermans, Bert; Kriesi, Hanspeter, \& Tarrow, Sidney G. (eds.) International social movement research. Greenwich: JAI Press

Gamson, William A., \& Modigliani, Andre (1987). The changing culture of affirmative action, pp. 137-177 in Braungart, Richard D. (ed.) Research in political sociology: A research annual. Greenwich: JAI Press.

Ganetz, Hillevi (2004). Familiar beasts: Nature, culture and gender in wildlife films on television. Nordicom Review, 25(1-2): 197-214.

Garrard, Greg (2012). Ecocriticism. London: Routledge.

Goffman, Erving (1974). Frame analysis: An essay on the organization of experience. New York: Harper \& Row.

Gottdiener, Mark (1995). Postmodern semiotics: material culture and the forms of postmodern life. Cambridge, Mass.: Blackwell.

Hansen, Anders, \& Machin, David (2013). Researching visual environmental communication. Environmental Communication, 7(2): 151-168.

Hartman, Steven (2007). The rise of American ecoliterature. American Studies in Scandinavia 39: 41-58. 
Haraway, Donna (2003). The companion species manifesto: Dogs, people, and significant otherness. Chicago: Prickly Paradigm Press.

Ingram, David (2000). Green screen: Environmentalism and Hollywood cinema. Exeter: University of Exeter Press.

Ivakhiv, Adrian (2008). Stirring the geopolitical unconscious: Towards a Jamesonian ecocriticism. New Formations: A Journal of Culture/Theory/Politics, 64: 98-109.

Jameson, Fredric (1995/1992). The geopolitical aesthetic: Cinema and space in the world system. Bloomington: Indiana University Press.

Jenkins, Henry (2009). Confronting the challenges of participatory culture. Cambridge: The MIT Press.

Kaika, Maria (2005). City of flows. Modernity, nature, and the city. New York: Routledge.

Katerberg, Will H. (2008). Future west: Utopia and apocalypse in frontier science fiction. Lawrence, KS: University Press of Kansas.

Lakoff, George (2010). Why it matters how we frame the environment. Environmental Communication, 4(1): 70-81.

Latour, Bruno (1993). We have never been modern. Cambridge, Massachusetts: Harvard University Press.

Macnaghten, Phil \& Urry, J. (1998). Contested natures. London: Sage.

Merchant, Carolyn (1990). The death of nature: Women, ecology, and the scientific Revolution. New York: HarperOne.

Merchant, Carolyn (2003). Reinventing Eden: The fate of nature in western culture. London: Routledge.

Milstein, Tema (2008). When whales "speak for themselves": Communication as a mediating force in wildlife tourism. Environmental Communication, 2(2): 173-192.

Milstein, Tema (2009). "Somethin' tells me it's all happening at the zoo": Discourse, power, and conservationism. Environmental Communication, 3(1): 25-48.

Oelschlaeger, Max (1991). The idea of wilderness. New Haven, CT: Yale University Press.

Olausson, Ulrika (2009). Global warming - global responsibility? Media frames of collective action and scientific certainty. Public Understanding of Science, 18(4): 421-436.

Olsen, Lester C., Finnegan, Cara A., \& Hope, Diane S. (2008). Visual rhetoric. A reader in communication and American culture. London: SAGE.

Ortner, Sherry B. (1974). Is female to male as nature is to culture? pp. 67-88 in Rosaldo, Michelle Z., \& Lamphere, Louise (eds.) Woman, culture, and society. Stanford, CA: Stanford University Press.

Peeples, Jennifer (2011). Toxic sublime: Imaging contaminated landscapes. Environmental Communication, 5(4): 373-392.

Pan, Zhongdang \& Kosicki, Gerald M. (1993). Framing analysis: An approach to news discourse. Political Communication, 10: 55-75.

Plumwood, Val (1997). Androcentrism and anthropocentricism: Parallels and politics, pp. 327-354 in Warren, Karen J. (ed.) Ecofeminism: Women, culture, nature. Bloomington: Indiana University Press.

Reese, Stephen D. (2007). The framing project: A bridging model for media research revisited. Journal of Communication, 57: 148-154.

Scheufele, Dietram A. \& Tewksbury, David (2007). Framing, agenda setting, and priming: The evolution of three media effects models. Journal of Communication, 21: 5-31.

Seegert, Natasha (2014). Queer beasts: Ursine punctures in domesticity. Environmental Communication, 8(1): 75-91.

Shehata, Adam \& Hopmann, David N. (2012). Framing climate change. Journalism Studies, 13(2): 175-192.

Sowards, Stacey K. (2006). Identification through Orangutans: Destabilizing the nature/culture dualism. Ethics \& the Environment, 11(2): 45-61.

Stiegler, Bernard (2009). The carnival of the new screen: From hegemony to isonomy, pp. 40-59 in Snickars, Pelle, \& Vonderau, Patrick (eds.) The YouTube reader. Stockholm: National Library of Sweden.

Stibbe, Arran (2001). Language, power, and the social construction of animals. Society and Animals, 9(2): 145-161.

Uggla, Ylva (2010). What is this thing called "natural". Journal of Political Ecology, 17: 79-91.

Uggla, Ylva \& Olausson, Ulrika (2013). The enrollment of nature in tourist information: Framing urban nature as "the other". Environmental Communication, 7(1): 97-112.

Willard, Barbara E. (2008). Special issue: Communication at the nexus of nature and culture. Environmental Communication, 2(2): 129-132.

Williams, Raymond (1980). Problems in materialism and culture. London: Verso.

ULRIKA OLAUSSON, Ph.D., Professor, School of Education and Communication, Jönköping University, ulrika.olausson@ju.se

CECILIA MÖRNER, Ph.D., School of Humanities, Education and Social Sciences, Örebro University 